\title{
Medicine and its Preventive Excesses
}

\section{A Medicina e os seus Excessos Preventivos}

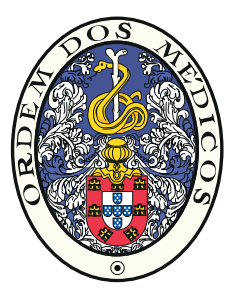

Juan GÉRVAS $\mathbb{M}^{1,2}$

Acta Med Port 2018 Feb;31(2):74-75 - https://doi.org/10.20344/amp.10288

Keywords: Medical Overuse; Preventive Medicine; Public Health

Palavras-chave: Medicina Preventiva; Saúde Pública; Uso Excessivo de Produtos e Serviços de Saúde

Medicine is a millenary practice in which components of science and custom are mixed with cultural and social expectations so that their activity manages to respond to human suffering, even in the face of death. In this sense, medicine has responded to a millennial contract, the curative contract, by which it offered attention to the sick human being to cure or alleviate suffering and it was admitted that this attention could cause damage. It was the patient's request that promoted the intervention of the doctor and there was an implicit agreement by which damages were accepted taking for granted the advantages of the benefits. For example, in the case of acute abdominal pain in the context of suspicion of appendicitis, in which the possibility of diagnostic error, surgical wound, anesthesia and its complications, etc. is accepted. The new, barely centenary and sole predominant contract since the second half of the last century, namely since the beginning of the Age of Risk Factors (from 1950 to 1999) ${ }^{1}$ is the preventive contract. In comparison with the curative contract, the preventive contract does not always respond to the patient's demand and almost never has to do with real and present suffering but with the possible and future one. Therefore, the preventive contract usually refers to healthy people, or apparently healthy, and requires that the possibilities of damage against huge benefits be almost negligible. A good example is the measles vaccine, which prevents this disease at the cost of producing one encephalitis per million vaccinations (among the unvaccinated who become ill, encephalitis occurs in one per thousand). If it is exercised with caution, medical activity gains a lot with the simultaneous existence of the curative contract and the preventive one. Unfortunately it is not usually the case, due to the unreasonable dominance of the preventive contract, which conveys the belief that it is always better to prevent than to cure. ${ }^{2,3}$

To illustrate the abuses of the preventive contract there is nothing like the overdiagnosis in the screening of neuroblastoma. Neuroblastoma is the most common extracranial solid cancer in childhood. Neuroblastoma often spreads to other parts of the body before any symptoms are apparent (up to $60 \%$ of all neuroblastoma cases present with metastases). Screening (via urine analysis) of asympto- matic infants at three weeks, six months, and one year has been performed in Austria, Canada, Germany and Japan since the 1980s. Screening was halted in 2004 after studies showed no reduction in deaths due to neuroblastoma, but rather caused an increase in diagnoses that would have disappeared without treatment, subjecting those infants to unnecessary surgery and chemotherapy. ${ }^{4}$ Neuroblastoma is one of the human malignancies known to demonstrate spontaneous regression from an undifferentiated state to a completely normal and benign cellular appearance..$^{5-7}$

'Overdiagnosis' is this increase in diagnosis that causes harms without benefits. Cancer overdiagnosis is the diagnosis of a 'cancer' that would otherwise not go on to cause symptoms or death. Overdiagnosis is an error of prognosis. Overdiagnosis is not an error of diagnosis. Overdiagnosis is an error regarding the expected impact of cancer on the quality of life and life expectancy. Overdiagnosis may lead to patient harm (through medical interventions) without any benefits. Overdiagnosis is a problem in breast cancer, cervical cancer, ovarian cancer, prostate cancer, lung cancer, thyroid cancer, colorectal cancer and melanoma screening.

The overdiagnosis of cancer has become a public health problem through the increase in screening (also by the increased use of diagnostic tests in general, especially imaging tests such as helical CT) but cancer screening trials seldom quantify the harms of screening. ${ }^{8}$ For example, we can decrease harms decreasing the 'intensivity' of the screening: compared to the less intensive screening practice in the Netherlands, US practice of cervical cancer screening may have resulted in two- to threefold higher harms, while the effects on cervical cancer incidence and mortality are similar. ${ }^{9}$

Overdiagnosis harms also family members as cancer screening and 'scrutiny-dependent' cancers is a snow ball. The push for 'early detection' leads to more scrutiny-dependent cancers being found which, in turn, gives the false impression of an increased incidence of some cancers. Aggressive screening of the family members of someone with cancer means more cancer will be found. This could give the impression of family history being more of a risk factor than it may actually be. ${ }^{10}$

The excesses of prevention are not limited to cancer

\footnotetext{
1. Retired Rural General Practitioner. Madrid. Spain.

2. Visiting Professor. National School of Public Health. Madrid. Spain.

$\triangle$ Autor correspondente: Juan Gérvas. jjgervas@gmail.com

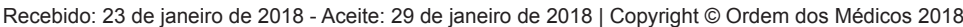


screening because they cover almost all preventive activities. Here are some examples to give an idea of the problem: general health check-ups, excessive tetanus vaccination, prenatal diagnosis with fetal DNA without warning the mother about the results about herself, screening for aortic aneurysm in women, early diagnosis of Alzheimer's disease, scoliosis screening at school, routine Doppler-electronic fetal monitoring, episiotomy, atrial fibrillation screening, screening for $\mathrm{HCV}$ in adults who are not at elevated risk, scanning the carotid artery, screening for the detection of atrial fibrillation, etc.

Part of the problem depends on a demanding population which leads to a negligent professional response. As such, we need to remember that the relationship between the medical profession and the public is changing but what has not changed is the fact that the public needs doctors

\section{REFERENCES}

1. Stontelberg C. Merging genetics and epidemiology. Scand J Public Health. 2005;33:1-3.

2. Gérvas J, Starfield, B, Heath I. Is clinical prevention better than cure? Lancet. 2008;372:1997-9.

3. Starfield B, Hyde J, Gérvas J, Heath I. The concept of prevention: a good idea gone astray? J Epidemiol Community Health. 2008;62:580-3.

4. Tsubono $\mathrm{Y}$, Hisamichi S. A halt to neuroblastoma screening in Japan. $\mathrm{N}$ Engl J Med. 2004;350:2010-1.

5. Carlsen NL. How frequent is spontaneous remission of neuroblastomas? Implications for screening. Br J Cancer. 1990;61:441-6.

6. Ricci SB, Cerchiari U. Spontaneous regression of malignant tumors: Importance of the immune system and other factors. Oncol Lett. 2010;1:941-5.

7. Brodeur GM. Spontaneous regression of neuroblastoma. Cell Tissue who are knowledgeable, skilled, ethical and committed. ${ }^{11}$

So, what shall we do? "All screening/prevention programmes do harm; some do good as well, and, of these, some do more good than harm at reasonable cost. The first task of any public health service is to identify beneficial programmes by appraising the evidence. However, evidence of a favourable balance of benefit to harm in a research setting does not guarantee that a similar balance will be reproduced in practice, so screening/prevention programmes need to be introduced in a way that allows their quality to be measured and continuously improved". ${ }^{12}$ This is important, given the potential for serious harms in healthy individuals. The determination of benefit from screening/prevention requires assessment in randomised clinical trials, which are also capable of providing high quality evidence on harms.

Res. 2018. (In press).

8. Heleno B, Thomsen MF, Rodrigues DS, Jørgensen KJ, Brodersen J. Quantification of harms in cancer screening trials: literature review. BMJ. 2013;347:f5334.

9. Habbema D, Weinmann S, Arbyn M, Kamineni A, Williams AE, M C M de Kok I, et al. Harms of cervical cancer screening in the United States and the Netherlands. Int J Cancer. 2017;140:1215-22.

10. Welch HG, Brawley OW. Scrutiny-dependent cancer and self-fulfilling risk factors. Ann Intern Med. 2018;168:143-4

11. Irvine $D$. The changing relationship between the public and the medical profession. J R Soc Med. 2001;94:162-9.

12. Gray JA, Patnick J, Blanks RG. Maximising benefit and minimising harm of screening. BMJ. 2008;336:480. 